\title{
Mapeamento de publicações sobre o ensino da química verde no Brasil a partir de redes sociais
}

Mapping of publications on the teaching of green chemistry in Brazil from social networks

\author{
Juliana Barreto Brandão \\ Júlia Damazio Bouzon² \\ Taís Conceição dos Santos ${ }^{3}$ \\ Valéria Pereira ${ }^{4}$ \\ Álvaro Chrispino ${ }^{5}$
}

\section{Resumo}

Nas últimas décadas, as questões ambientais têm merecido destaque tanto no cenário nacional quanto internacional, sendo o início da década de 1990 marcada pelo nascimento da Química Verde. O presente trabalho trata-se de uma pesquisa do estado da arte sobre Química Verde na área de Ensino de Ciências e foi construído a partir da análise bibliométrica e de redes com 31 artigos selecionados a partir de pesquisa em 260 revistas nacionais indexadas em Qualis A1, A2 e B1 pela Coordenação de Aperfeiçoamento de Pessoal de Nível Superior (CAPES), na área de Ensino. A partir da análise das redes e da leitura das obras mais referenciadas, pudemos entender a relevância desta área para o Ensino de Ciências brasileiro, tendo como autores mais produtivos: Carlos Alberto Marques e Vânia Zuin; referências teóricas mais buscadas: Green Chemistry - Os 12 princípios da Química Verde e sua inserção nas atividades de ensino e pesquisa e Green Chemistry: theory and practice e os autores mais citados: Wildson Santos e Paul Anastas.

Palavras chave: química verde; ensino de química; redes sociais.

\section{Abstract}

The Green Chemistry term was born in the years of 1990. From that on, in the last decades, environmental issues of national and international context have been more careful. This article presents the highest level of Green Chemistry research in teaching science area. It was developed from bibliometric analysis and networks with 31 articles selected from the research in 260 national journals indexed with qualis A1, A2 and B1 by the Coordenação de Aperfeiçoamento de Pessoal de Nível Superior (CAPES), in the teaching area. By the

\footnotetext{
${ }^{1}$ Centro Federal de Educação Tecnológica Celso Suckow da Fonseca | profjulianabrandao@gmail.com

${ }^{2}$ Colégio Pedro II | juliabouzon@gmail.com

${ }^{3}$ Centro Federal de Educação Tecnológica Celso Suckow da Fonseca | taisquim@hotmail.com

${ }^{4}$ Centro Federal de Educação Tecnológica Celso Suckow da Fonseca | valnppn@gmail.com

${ }^{5}$ Centro Federal de Educação Tecnológica Celso Suckow da Fonseca | alvaro.chrispino@gmail.com
} 
networks analysis and the most cited works reading, we could understand how relevant this area is to the science teaching in Brazil. Besides this, Carlos Alberto Marques and Vânia Zuin were the most productive authors found. The most researched theory referential were found to be: Green Chemistry - os 12 princípios da química verde e sua inserção nas atividades de ensino e pesquisa and Green Chemistry: theory and practice. Last but not least, Wildson Santos and Paul Anastas were the most cited authors.

Keywords: green chemistry; chemistry teaching; social networks.

\section{Introdução}

Meados do século XVIII e a Inglaterra presenciaria a primeira fase da Revolução Industrial sem desconfiar que isso impactaria o mundo sem precedentes. O extrativismo, da forma como até então era realizado, a mão de obra artesanal, a produção manual, limitada e sem rigor quanto às padronizações estavam com seus dias marcados.

"Vendo aqui, senhor, o que o mundo inteiro deseja ter - Energia". Com esse pensamento Matthew Boulton e James Watt impulsionando a Revolução Industrial, foram pioneiros no uso das máquinas a vapor, que utilizariam a queima do carvão mineral para alimentá-las (BYNUM, 2013). Esse combustível foi dando espaço ao longo dos anos aos derivados do petróleo, também de origem fóssil. E, em um pouco mais de dois séculos desse marco, 75,5\% da energia que move o mundo, ainda advém dessas fontes (REN21, 2017).

O desenvolvimento da indústria química alavancado nos séculos XIX e XX possibilitariam ao homem, nos anos posteriores, conforto, longevidade maior, avanços na área tecnológica, farmacêutica e aumento da produtividade e mecanização nos campos, com o uso de defensivos agrícolas químicos. Muitas substâncias naturais foram gradativamente substituídas pelas sintéticas que tinham a seu favor a padronização, resistência à degradação e menor custo se comparadas às anteriores.

Os processos químicos se aprimoraram e mais empresas somaram-se a esse cenário na tentativa de sintetizar substâncias que poderiam substituir as fibras naturais como o algodão, a juta e a seda, assim como materiais como a borracha natural e o marfim. Surgiram o nylon, a borracha sintética, o polietileno e a baquelite que somados aos outros tantos que viriam, mudaram, além de outros fatores e segmentos, o mobiliário tradicional, o vestuário, os meios de comunicação, a indústria automobilística e até a de entretenimento.

Um artigo da Revista Science Advances, apresentou a primeira análise global de todos os plásticos produzidos em massa já fabricados no mundo (GEYER et al, 2017). Segundo seus autores, desde 1950, ano em que foram produzidos pela primeira vez, até 2015, a quantidade de plásticos virgens ou ditos de primeira linha, encontra-se na ordem de 8300 milhões de toneladas. Foram gerados como resíduos até a última data analisada, 6300 milhões de toneladas onde apenas 9\% desse valor foi reciclado, 12\% destinaram-se a incineração e 79\% desse montante estão acumulados em aterros sanitários ou encontramse livres em ambientes naturais. Estima-se que esse valor dobre até o ano de 2050, se nenhuma medida for tomada até lá.

De forma muito intensa, desde a primeira Revolução Industrial até os dias atuais, o planeta Terra tornou-se pesado, pela imensa quantidade de resíduos que acumula, adoecido por um ar com um grande número de particulados sólidos, além de uma gama 
de gases poluentes que agravam o aquecimento, acentuam a chuva ácida ou interferem na camada protetora de ozônio.

Sem noção da repercussão que causaria ou mesmo de leis rígidas de controle ambiental, o homem seguiu em estado caótico até o século XX, contaminando rios e mares por efluentes industriais sem tratamento prévio ou mesmo interferindo na elevação da temperatura do planeta, contribuindo de uma forma ou de outra, para o desequilíbrio dos biomas aquáticos. O impacto já causado ao meio ambiente pelo descaso no tratamento de efluentes ou no destino dos resíduos químicos gerados pela produção industrial aliado à necessidade de um controle de degradação em áreas ambientais e a preocupação crescente com a qualidade do ar e dos biomas do planeta, fomentou, na década de 1990, a criação da agência norte americana EPA (Environmental Protection Agency). Essa agência foi a pioneira a incentivar os projetos de pesquisa de rotas sintéticas que minimizassem os impactos que causariam ao meio ambiente, diminuindo dessa forma a poluição. Nesse contexto e com essa ambição, o termo Química Verde (QV) ou ainda Química Sustentável, foi cunhado e percebido como ações que ponderassem os processos a serem seguidos pela indústria química. A prioridade seria analisar as rotas químicas existentes, reduzindo-as ou mesmo eliminando-as, no intuito de gerar um mínimo de resíduos, estimulando, por conseguinte, inovações tecnológicas verdes.

A EPA junto a ACS (American Chemical Society) elaboraram doze princípios que estruturaram e definiram a QV e que vão além da proposição de novas rotas, a citar: evitar a formação de resíduos; ; incorporar todos os átomos dos reagentes nos produtos ${ }^{2}$; gerar sempre que possível produtos de que não ofereçam risco ${ }^{3}$; programar os produtos para que cumpram sua função com toxidez baixa ${ }^{4}$; usar minimamente os solventes, secantes ou qualquer outra substância secundária ao processo (sendo imprescindível esse uso, que sejam o mais inócuos possíveis); ${ }^{5}$ estruturar processos que ocorram na temperatura e pressão ambientes, evitando sempre que possível o desperdício de energia ${ }^{6}$; utilizar preferencialmente matérias primas de fontes renováveis; ; evitar a formação de derivados nas reações escolhidas ${ }^{8}$; usar reagentes catalíticos com seletividade alta ${ }^{9}$; descartar reações que ao final se degradem e formem resíduos tóxicos ${ }^{10}$; controlar em tempo real o andamento de uma reação, atuando sempre na prevenção da formação de algum produto indesejável ${ }^{11}$ e prevenir a ocorrência de acidentes, como vazamentos, explosões e incêndios prejudicando os diretamente envolvidos no processo bem como ao meio ambiente ${ }^{12}$ (CORREA e ZUIN, 2009).

Muito embora a QV esteja imbuída de princípios de grande valia à garantia da sobrevivência da humanidade ao planeta, ela ainda habita quase que exclusivamente na esfera industrial, transitando pouco na área de Ensino. Seus doze princípios são voltados para processos industriais e, aparentemente, o termo QV, quando presente na área de Ensino, aparece reduzido ou associado ao termo Química Ambiental.

No que concerne à área de Ensino, Zuin (2008) ressalta que somente a partir de 2007 algumas universidades começaram a implantar discussões sobre a QV voltadas para o ensino superior e a pós-graduação e que frequentemente essa temática vem sendo mais discutida. Por outro lado, a indicação de reformas educacionais, como a implantação da Base Nacional Comum Curricular, traz à tona debates e reflexões sobre a inserção da QV no contexto educacional. Nesse cenário, Pitanga (2016) destaca que os currículos que contemplam os princípios da QV proporcionam a compreensão ampliada dos impactos 
causados pela química, diminuindo as lacunas existentes entre a sala de aula e o ambiente como um todo.

No entanto, a inserção desses conceitos no ensino não é tão simples, uma vez que deve levar em consideração a participação de toda a comunidade escolar. Segundo Teixeira, Agudo e Talamoni (2015, p. 73),

Um aspecto a ser considerado no processo educativo ambiental refere-se à relação dialógica e participativa entre a escola e a comunidade, pois, embora no discurso esta participação possa estar enfatizada, sabemos de sua fragilidade. O ponto fulcral está na qualidade da articulação e da participação, comprometendo a capacidade de atuação dos sujeitos envolvidos nos processos dialógicos de organização, comunicação e decisão (TEIXEIRA, AGUDO e TALAMONI, 2015, p. 73).

Assim, a aproximação multidisciplinar para uma educação em QV pode desenvolver nos alunos uma comunicação interdisciplinar e facilitar contatos que promovam uma concentração de esforços para enfrentar os problemas e desenvolver tecnologias sustentáveis (BRAUN et al, 2006).

Além disso, o enfoque Ciência-Tecnologia-Sociedade (CTS) se aproxima da QV uma vez que, segundo Auler e Bazzo (2001) e Santos e Mortimer (2002), esta abordagem pode contribuir com o Ensino de Química, tendo em vista que tal temática objetiva justamente um ensino mais crítico e contextualizado, promovendo a participação da sociedade em questões relacionadas ao avanço científico-tecnológico.

Por outro lado, o mapeamento de obras acadêmicas cada vez mais se torna importante devido à quantidade de informações provenientes desse tipo de estudo. Os estudos bibliométricos surgiram no século XX e nesse contexto, Maricato e Noronha (2013, p. 61) ressaltam que a bibliometria "engloba o estudo dos aspectos quantitativos da produção, disseminação e uso da informação registrada, desenvolvendo modelos e medidas matemáticas, com a função para elaborar previsões e apoiar tomadas de decisões". O grupo CTS e Educação, do CEFET/RJ, vem se dedicando ao mapeamento da área de CTS em Ensino no Brasil por meio da análise de redes sociais. $O$ trabalho pioneiro foi o de Chrispino et al. (2013); seguido por Melo et al. (2016a) e Rocha et al, (2017).

Neste contexto, esse artigo visa analisar a representatividade do ensino de QV na área de Ensino no Brasil, a partir da análise de Rede Social e, por esse meio, investigar as principais palavras-chave, os autores que produzem nessa área e o que está sendo produzido em nosso país sob essa temática.

\section{Metodologia}

Para o desenvolvimento desta pesquisa, consultamos a base de dados da Coordenação de Aperfeiçoamento de Pessoal do Ensino Superior (CAPES) indexadas com Qualis A1, A2 e B1, onde foram levantadas 260 revistas. A partir da busca individual da expressão "Química Verde" nos sítios de cada revista, seja na palavra-chave, resumo e/ou texto, foram encontrados 31 artigos (Anexo 1), publicados até o $1^{\circ}$ semestre de 2017, que foram nosso objeto de estudo.

As revistas que contêm os artigos selecionados e que constam nesse banco de dados são: Pesquisa em Educação Ambiental, Revista Brasileira de Ensino de Química, Química 
Nova na Escola, Biota Amazônia, Revista Ciência e Tecnologia, Revista Cultivando o Saber, Revista Educação e Tecnologia, Ensaio: Pesquisa em Educação em Ciências, Alexandria, Comciência, Investigações em Ensino de Ciências, Matéria, Movimento e RBPG - Revista Brasileira de Pós-Graduação.

Como ferramenta de trabalho, optamos pela Análise de Rede Social que, através de grafos, possibilita perceber a interação entre entes diversos dentro de um universo. Neste caso, foi feita uma rede das 66 palavras-chave, contidas nos artigos, a fim de analisar de que maneira os trabalhos de QV se relacionam entre si. Além disso, outra rede foi gerada a partir dos 77 autores dos artigos pesquisados objetivando investigar se há alguma relação entre os mesmos.

Para Melo et al (2016b),

[...] a análise de redes nos permite ter uma visão panorâmica de como se comporta uma área, seja ela CTS ou qualquer outra. A metodologia escolhida, ainda que não tão popular quanto outras na área de ensino, apresenta uma visão dos dados capaz de trazer amplitude e o tratamento de um número elevado de dados. Assim como metodologias de análise de conteúdo e suas derivadas, ela apresenta categorizações retiradas do próprio material de análise, porém, não de forma qualitativa, mas quantitativa. Isso permite que trabalhemos tantos artigos quantos a literatura nos dispuser (MELO et al, 2016b, p. 594 e 595).

Mesmo que uma rede, a princípio, nos traga apenas dados quantitativos, ela ainda nos permite fazer uma análise qualitativa a respeito dos dados, como foi justificado por Chrispino et al (2013):

A maneira viva como se processam as inter-relações nas redes sociais sugere uma abordagem complexa e inclusiva. Por tal, todas as nuances e possibilidades de comunicação devem ser consideradas, constituindo, assim, um ambiente dinâmico de múltiplas relações que só adquirem significado total quando se contempla sua completude. (CHRISPINO et al, 2013, p. 459)

A rede deste trabalho foi gerada no software NodeX $L^{6}$ que, além de gerar o grafo, permite calcular medidas de centralidade. A fim de evitar resultados que sejam muito heterogêneos, foram criadas algumas equivalências, como, por exemplo, substituir as palavras-chave "CTSA" por "CTS", "Formação de professores" por "Formação docente", "Sustentabilidade ambiental" por "Sustentabilidade", "Ensino interdisciplinar" por "Interdisciplinaridade", dentre outras do mesmo tipo. As medidas de centralidade são graus que indicam as posições dos vértices de uma rede e podem ser de diferentes tipos, como por exemplo: de grau, de proximidade (closeness) e de intermediação (betweenness), dentre outras. Nesse caso, usaremos as medidas de centralidade citadas anteriormente.

A medida de centralidade de grau de entrada aponta quantas arestas se ligam a um vértice da rede. Sendo assim, quanto maior for a centralidade de grau, mais relações esta palavra-chave possui com outras. A medida de centralidade de proximidade (closeness) mede a distância da ligação entre os vértices, o que significa que quanto maior for o grau

\footnotetext{
${ }^{6}$ A versão utilizada está disponível no site http://nodexl.codeplex.com
} 
de proximidade, menor é a distância entre duas palavras-chave e, consequentemente, maior é a comunicação entre elas. Em contrapartida, a medida de centralidade de intermediação (betweenness) indica a capacidade que um vértice tem de relacionar duas sub-redes, ou seja, de que forma uma palavra-chave consegue intermediar dois ou mais artigos no menor caminho entre eles. De acordo com Marteleto (2001), a centralidade de intermediação significa

[...] o potencial daqueles que servem como intermediários. Calcula o quanto um ator atua como "ponte", facilitando o fluxo de informação em uma determinada rede. Um sujeito pode não ter muitos contatos, estabelecer elos fracos, mas ter uma importância fundamental na mediação das trocas. O papel de mediados traz em si a marca do poder de controlar as informações que circulam na rede e o trajeto que elas podem percorrer (MARTELETO, 2001, p. 79).

Depois da rede gerada, foram selecionados, a fim de recorte de pesquisa, os 8 vértices do grafo de palavras-chave e os 2 vértices do grafo de autores que apresentavam maior grau de entrada e organizou-se uma tabela para cada rede com os dados das diversas medidas de centralidade para posterior análise.

Além disso, com o objetivo de apresentar um resumo sobre as referências mais citadas e um breve panorama sobre a história dos primeiros autores mais relevantes neste campo, duas outras tabelas foram montadas a partir dos 31 artigos relacionados à Química Verde: a primeira contendo as obras mais citadas por esses artigos e a outra com os primeiros autores mais referenciados pelos mesmos.

\section{Resultados}

Inicialmente, foi feita uma análise a respeito da quantidade de publicações relacionadas à QV e o ensino ao longo dos anos. É notório que esse número é extremamente reduzido, mas vem em um crescente, como pode ser visto no Gráfico 1. Este dado pode ser explicado pelo fato da QV ainda ser um tema de baixo conhecimento para muitos docentes e estar ganhando uma visibilidade maior devido às reformas curriculares e a necessidade de contextualização e uma preocupação maior de conscientizar os estudantes a respeito das decisões a serem tomadas quando questionados a respeito de conteúdos fora de sala de aula.

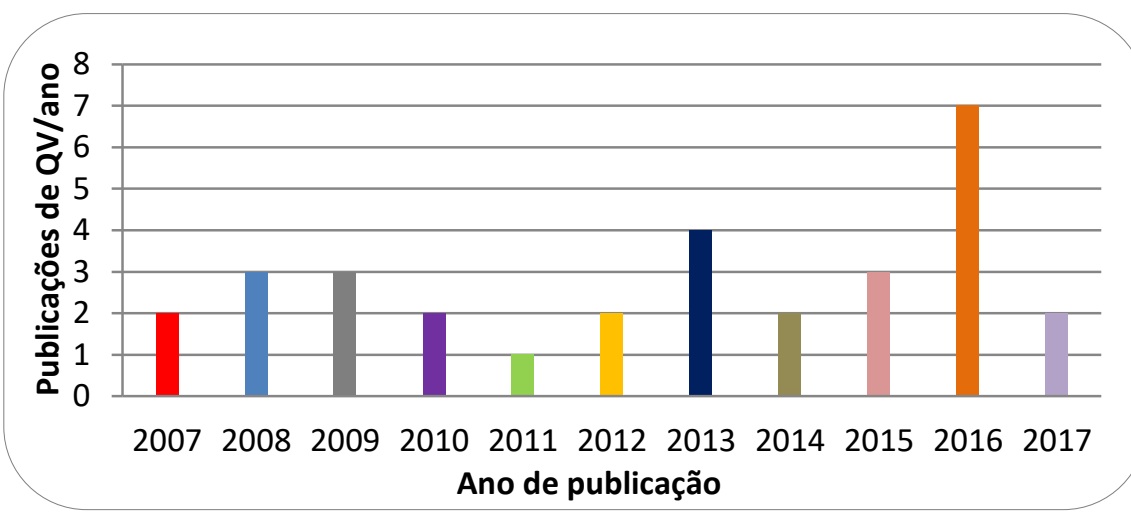

Gráfico 1 - Publicações de Química Verde por ano. 
Além desta análise, foi feito um mapeamento a respeito das revistas que publicam nesta área. Das treze revistas que possuíam algum artigo deste viés, destacam-se a revista Química Nova na Escola com 11 publicações e a Revista Brasileira de Ensino de Química com 7 trabalhos. Algumas revistas aparecem com apenas duas publicações (Educação e Tecnologia; Ensaio: Pesquisa em Educação em Ciências), enquanto as demais publicaram apenas uma vez na área de QV: Pesquisa em Educação Ambiental, Biota Amazônia, Revista Ciência e Tecnologia, Revista Cultivando o Saber, Alexandria, Investigações em Ensino de Ciências, Matéria, Movimento e RBPG - Revista Brasileira de Pós-Graduação.

Investigou-se, também, o vínculo dos autores com as suas instituições de ensino. É importante dizer que nenhum autor foi vinculado a mais de uma instituição e, mesmo que possuíssem autoria em mais de um trabalho, a instituição de ensino a qual são vinculados foi contabilizada apenas uma vez. Além disso, é válido acrescentar que, no Gráfico 2, constam apenas as instituições que possuem 2 ou mais autores pertencentes a mesma e que publicam nesta área. Podemos concluir, então, que a maioria das entidades possui apenas um autor e, por isso, não aparecem evidenciadas. Em contrapartida, destacamos a USP e a UNESP que possuem 8 autores publicando.

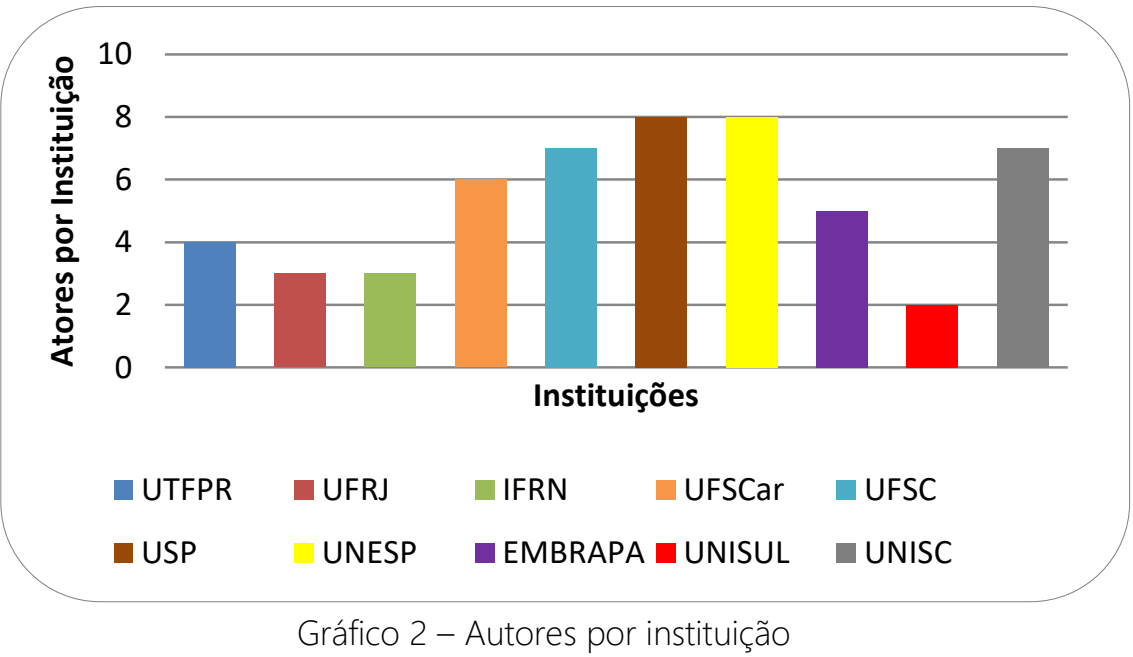

A partir da organização das palavras-chave no software citado, gerou-se um grafo como mostra a figura 1.

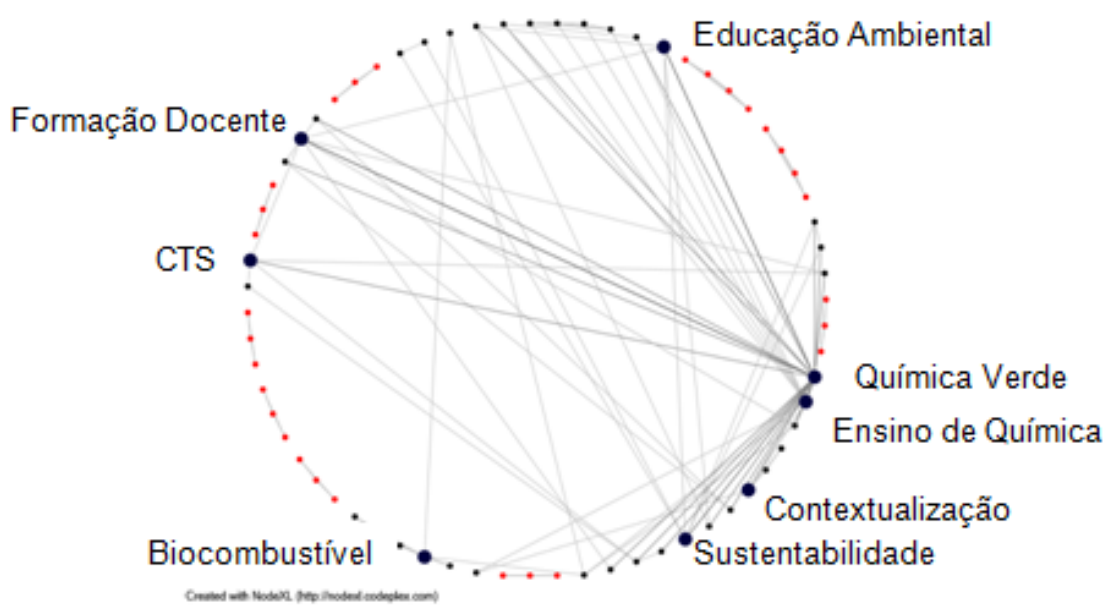

Figura 1 - Grafo gerado a partir das palavras-chave 
Neste grafo, podemos observar de que maneira as palavras-chave se relacionam entre si. Os vértices maiores correspondem às oito que possuem maior grau de entrada, ou seja, aquelas que possuem maior conexão com outros vértices. Além disso, destacamos em vermelho as redes desconexas, que são assim denominadas por não possuírem nenhum vínculo com palavras-chave de outras sub-redes e só se relacionarem entre si. Apesar de serem artigos referentes ao tema de QV, a escolha destas palavras-chave não contribui para que a comunidade científica desta área tenha tanto conhecimento destes trabalhos, uma vez que grande parte das pesquisas são feitas a partir das palavras-chave e não de forma tão abrangente quanto o nosso trabalho. Ou seja, é importante ressaltar que, caso tivéssemos pesquisado apenas pelas palavras-chave, não contaríamos com estes artigos para posterior análise. Tal fato deve merecer atenção dos especialistas da área.

Além da centralidade de grau, também podemos analisar as medidas de centralidade de proximidade e de intermediação, conforme os dados da tabela abaixo (tabela 1).

Tabela 1 - Medidas de centralidade para as palavras-chave

\begin{tabular}{cccc}
\hline Palavra-chave & $\begin{array}{c}\text { Centralidade } \\
\text { de Grau }\end{array}$ & $\begin{array}{c}\text { Centralidade de } \\
\text { proximidade }\end{array}$ & $\begin{array}{c}\text { Centralidade de } \\
\text { intermediação }\end{array}$ \\
\hline Química Verde & 20 & 0,016 & 434,433 \\
\hline Ensino de Química & 11 & 0,014 & 249,800 \\
\hline Formação Docente & 6 & 0,011 & 16,233 \\
\hline Sustentabilidade & 6 & 0,011 & 71,000 \\
\hline Biocombustível & 6 & 0,008 & 136,000 \\
\hline Contextualização & 5 & 0,012 & 79,333 \\
\hline Educação Ambiental & 5 & 0,011 & 5,500 \\
\hline CTS & 5 & 0,011 & 20,200 \\
\hline
\end{tabular}

Os dados da tabela 1, em consonância com a análise do grafo, nos permitem identificar que "Química Verde" e "Ensino de Química" são duas palavras-chave que possuem as maiores medidas de centralidade. Isso indica um maior poder de comunicação destas palavras com as demais que constituem a rede, bem como maior capacidade que as mesmas têm de relacionar artigos diferentes. Em relação ao primeiro termo, isto era esperado, uma vez que essa palavra caracteriza o objeto principal dessa pesquisa.

O interessante é ver que "Ensino de Química" e "Formação Docente" vêm logo após o tema principal, evidenciando que, apesar de QV ainda não ser tão discutido em sala de aula, este é um tema que está ganhando bastante espaço. Além disso, é importante ressaltar que a maioria das palavras-chave de maior relevância possui relação com CTS que é, inclusive, uma delas. Isto nos evidencia que, quando aliados, a QV e a abordagem CTS podem ser uma estratégia de ensino que faz com que o estudante se torne mais crítico e tenha maior capacidade de escolha quando questionado a respeito, principalmente em relação à parte ambiental.

A fim de investigar como os autores dos 31 artigos em análise se relacionam, construímos também uma rede com os 77 autores desses trabalhos, cujo resultado pode ser visto no grafo esquematizado na figura 2.

Assim como no grafo anterior, os vértices de maior tamanho indicam os dois autores que apresentaram maior centralidade de grau, ou seja, aqueles que estabelecem maior relação com os demais autores. O primeiro é o professor Carlos Alberto Marques, do departamento de Metodologia de Ensino da Universidade Federal de Santa Catarina. Ele tem pós-doutoramento em Ensino da Química Verde e atuação ativa na área tanto no 
desenvolvimento de projetos de pesquisa quanto em produção bibliográfica. Em seguida, destaca-se a pesquisadora Vânia Zuin, professora do departamento de Química da Universidade Federal de São Carlos, com extensa atuação na área de QV, inclusive na esfera internacional, sendo uma das autoras mais citadas nos artigos em análise, como será visto mais adiante.

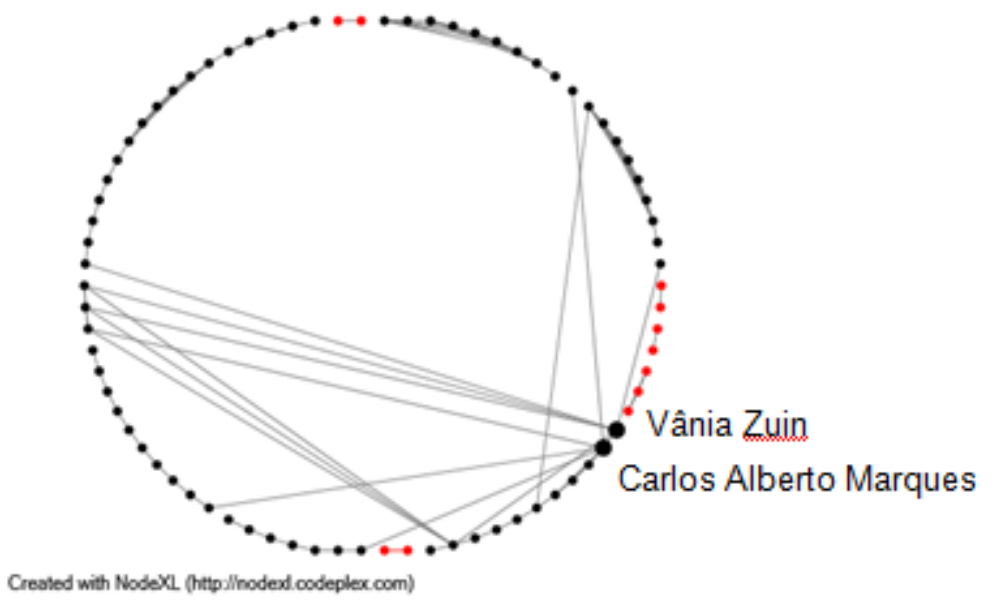

Figura 2 - Grafo gerado a partir dos autores

A participação ativa desses profissionais no ensino da QV também justifica os altos valores de centralidade de intermediação obtidos na rede, isto é, eles são os que têm maior capacidade de diálogo com autores de outras sub-redes, como mostra a Tabela 2.

Tabela 2 - Medidas de centralidade para os autores dos artigos em análise

\begin{tabular}{cccc}
\hline Autor & $\begin{array}{c}\text { Centralidade } \\
\text { de Grau }\end{array}$ & $\begin{array}{c}\text { Centralidade de } \\
\text { Intermediação }\end{array}$ & Instituição de Vínculo \\
\hline Carlos Alberto Marques & 8 & 1058,750 & Universidade Federal de Santa Catarina \\
\hline Vânia Gomes Zuin & 7 & 799,500 & Universidade Federal de São Carlos \\
\hline
\end{tabular}

A análise do grafo também nos permite concluir que os autores de determinadas subredes não estabelecem nenhum diálogo entre si. Estas são consideradas redes desconexas e estão destacadas em vermelho na Figura 2.

Além dessa análise, também foi feito um levantamento das obras utilizadas como referências para a elaboração desses trabalhos, totalizando 650 citações. Dessas, destacamos na Tabela 3 as seis mais citadas.

A primeira obra mais referenciada, Green Chemistry - os 12 princípios da Química Verde e sua inserção nas atividades de ensino e pesquisa, é um artigo que destaca que a QV nasceu QV com o propósito de atuar diretamente na redução e controle de resíduos gerados e não no seu tratamento. Além disso, apresenta e discute "os fundamentos da QV, além de um breve histórico sobre seu surgimento e desenvolvimento, mostrando ainda aplicações dos princípios da QV na indústria, no ensino e na pesquisa básica em química." (LENARDÃO et al, 2003, p.123).

O desenvolvimento do texto apresenta um conceito para QV, termo mais utilizado e que foi adotado pela IUPAC, embora existam outros que também definem a mesma ideia. Na sequência, cita e explica os doze princípios da QV, apresentando para cada um, exemplos práticos da indústria e que podem ser estendidos para o Ensino de Química. 
Tabela 3 - Obras mais citadas nos artigos sobre Química Verde

\begin{tabular}{ccl}
\hline Posição & $\begin{array}{c}\text { Número de } \\
\text { Citações }\end{array}$ & \multicolumn{1}{c}{ Obra } \\
\hline 1 & 8 & $\begin{array}{l}\text { Lenardão, E. J. et al (2003). Green Chemistry - os } 12 \text { princípios da Química Verde e sua } \\
\text { inserção nas atividades de ensino e pesquisa. }\end{array}$ \\
\hline 2 & 5 & Anastas, P. T.; Warner, J. C. (1998). Green Chemistry: theory and practice. \\
\hline 3 & 5 & Freire, P. (1997). Pedagogia do oprimido. \\
\hline 4 & 4 & $\begin{array}{l}\text { Santos, W. L. P.; Schnetzler, R. P. (2008). Educação em Química: Compromisso com a } \\
\text { Cidadania. }\end{array}$ \\
\hline 6 & 4 & $\begin{array}{l}\text { Santos, W. L. P.; Mortimer, E. F. (2002). Uma análise de pressupostos teóricos da } \\
\text { abordagem CTS (Ciência - Tecnologia, Sociedade) no contexto da educação brasileira. }\end{array}$ \\
\hline & 4 & $\begin{array}{l}\text { Marques, C. A. et al (2007). Visões de meio ambiente e suas implicações no ensino de } \\
\text { química na escola média. }\end{array}$ \\
\hline
\end{tabular}

Partindo do mesmo viés, Green Chemistry: theory and practice é um livro que originalmente apresentou os doze princípios da QV e aparece como a segunda obra mais citada. Este livro é considerado como a base da QV e tem grande reconhecimento internacional, sendo muito utilizado por instituições de ensino e também pela indústria. É uma referência muito relevante e, talvez, não apareça na primeira posição por não ser uma obra escrita em português. Dessa forma, tanto o artigo quanto o livro são referências muito esclarecedoras para aqueles que almejam não só estudar, mas fazer desses princípios uma prática cotidiana. Indivíduos sensibilizados e formados dentro desses princípios, provavelmente terão mais chances de se perceberem parte fundamental do meio ambiente e, assim, pensar e atuar de modo mais eficiente diante de situações relacionadas ao mesmo.

Na sequência, as terceira, quarta e quinta posições são ocupadas por obras que não falam diretamente sobre QV, mas trazem componentes fundamentais para a compreensão e o debate sobre o ensino nessa vertente.

Paulo Freire (1997) em Pedagogia do Oprimido, por exemplo, chama a atenção do leitor para o método de ensino "bancário" extremamente aplicado nas salas de aula da época e que perdura ainda nos dias de hoje. O livro clama pela superação de um ensino que se utiliza da deposição de conteúdos por outro que valorize a problematização e estimule o desenvolvimento do pensamento crítico dos indivíduos. Nesse contexto, se pensarmos no ensino da QV, essa discussão faz-se pertinente e necessária.

O livro Educação em Química: compromisso com a cidadania, de Santos e Schnetzler (2008) apresenta, em seus capítulos, a ideia de que o ensino de ciências deve promover a formação de indivíduos com pensamento crítico e visão crítica do meio que o cerca. Os conhecimentos científicos devem ser articulados de modo que os estudantes possam tomar decisões a respeito de problemas do dia a dia de modo mais consciente, bem como possam interagir com o mundo. A obra destaca que para isso, o conhecimento científico deve estar inter-relacionado com o contexto social. Neste sentido, propõe a utilização de uma abordagem temática para o ensino a partir de temas químicos sociais.

Partindo da mesma linha de pensamento, Santos e Mortimer (2002) destacam em seu artigo uma análise crítica sobre pressupostos de currículos de ensino de ciências com ênfase em Ciência-Tecnologia-Sociedade (CTS) e trazem à tona a importância do papel dos atores sociais no desenvolvimento científico-tecnológico, e a necessidade de se relacionar ciência e tecnologia num contexto social para a solução de problemas sobre temas de relevância social.

O sexto trabalho mais citado - Visões de meio ambiente e suas implicações no ensino de química na escola média - fala sobre a importância de discutir sobre as questões ambientais 
no contexto pedagógico e cita a abordagem CTS como um caminho para isso. Neste sentido, destaca a necessidade de introduzir essa discussão na formação inicial do professor. Em seguida, apresenta sua pesquisa com professores de Química do ensino médio de escolas localizadas em municípios de Florianópolis. Os docentes participaram de uma entrevista semi-estruturada com os objetivos de "identificar aspectos da prática pedagógica; analisar os possíveis modos de abordagem de temas em sala de aula; compreender as relações entre os seres humanos, a Química, o meio ambiente e as questões ambientais; e entender as dificuldades e/ou possibilidades para abordar questões ambientais nas aulas de Química" (MARQUES et al, 2007, p. 2045). Além disso, categorizaram as compreensões docentes predominantes sobre visão de meio ambiente, problemática ambiental e sua relação com a química e prática docente.

A análise da pesquisa mostrou que, embora, a maior parte dos professores tenha algum conhecimento sobre QV, a abordagem deste tema em sala de aula ainda é muito precária, por diversos motivos, como falta de estrutura da escola e formação acadêmica deficiente, dentre outros. Isso mostra a relevância da pesquisa nessa área no âmbito escolar e em todas as etapas do ensino.

Por fim, foi feito um levantamento sobre os primeiros autores mais citados nos artigos analisados, como mostra a Tabela 4, com o intuito de investigar suas influências no ensino da QV no Brasil.

Tabela 4 - Autores mais citados nos artigos sobre Química Verde

\begin{tabular}{ccc}
\hline Posição & Número de Citações & Autor \\
\hline 1 & 17 & Wildson Luiz Pereira dos Santos (Santos, W. L. P.) \\
\hline 2 & 14 & Paul T. Anastas (Anastas, P. T.) \\
\hline 3 & 11 & Paulo Freire (Freire, P.) \\
\hline 4 & 9 & Carlos Alberto Marques (Marques, C. A.) \\
\hline 5 & 9 & Vânia Gomes Zuin (Zuin, V. G.) \\
\hline
\end{tabular}

Ao realizar este estudo, percebemos, de forma surpreendente, que o mais referenciado é, na verdade, uma revista: a Veja, citada 25 vezes. Isso mostra que a maior parte dos trabalhos sobre ensino de QV se apoia no uso de reportagens sobre temas ambientais variados e não nos pressupostos de um determinado autor. Em segundo lugar (21 citações), temos as bases legais nacionais, o que já era esperado, visto que, nesse contexto, o embasamento na legislação ambiental é fundamental e necessário.

Wildson Luiz Pereira dos Santos é o autor que lidera as citações na área de QV. Licenciado em Química, mestre em educação pela UNICAMP (1992) e doutor na mesma área pela UFMG (2002), Wildson teve como último vínculo a Universidade de Brasília, além de ter atuado também, durante sua trajetória, no ensino médio. Este autor é também o mais citado e o que possui a obra mais referenciada no Ensino de Química dentro do cenário CTS brasileiro (CHRISPINO et al., 2013). Este fato pode ser explicado pelo seu vínculo com a Associação Ibero-americana Ciência-Tecnologia-Sociedade (AIA-CTS), onde desenvolveu diversas linhas de pesquisa sobre abordagem CTS.

Em segundo lugar, temos Paul T. Anastas, bacharel em Ciências (1984) pela Universidade de Massachusetts e doutor em Ciências (Brandeis University, 1989). É considerado o "pai" da QV e, por isso, fonte primária internacional de grande relevância, sendo autor de várias publicações na área, incluindo a segunda obra mais citada (Tabela 3). No momento, é diretor do Centro de Química Verde e Engenharia Verde da Universidade 
de Yale e professor na Prática da Química para o Ambiente em School of Forestry \& Environmental Studies.

Na sequência, vemos que o terceiro autor mais relevante para o ensino de QV é Paulo Freire que, apesar de ser formado em direito, contribuiu com pensamentos muito relevantes para a educação. Caracterizado pelo seu método inovador de alfabetizar os estudantes, Freire foi pedagogo e gestor na área de educação em Pernambuco e, além de atuar em muitos países, retornou ao Brasil onde foi Secretário da Educação da cidade de São Paulo e elaborou um programa público para a educação de jovens e adultos. Paulo Freire deixou diversas obras extremamente relevantes como Pedagogia do Oprimido e, mesmo falecendo em 1997, é um autor citado com frequência uma vez que prezava pela formação de cidadãos transformadores de ordem social, econômica e política injusta.

Por fim, nas quarta e quinta posições aparecem Carlos Alberto Marques e Vânia Gomes Zuin, respectivamente, que são dois autores de participação muito ativa na área, com publicações e projetos de pesquisa em desenvolvimento, como dito anteriormente.

Carlos Alberto Marques aparece como o quarto autor mais citado. Ele é licenciado e bacharel em Química pela UFSC (1988), mestre em Química (1991) pela mesma universidade e doutor em Ciências Químicas na Universitá Degli Studi di Venezia (Itália, 1995). Fez pósdoutorado também na Itália (2010) em Ensino da QV. Atualmente é professor titular do Departamento de Metodologia de Ensino da UFSC e ministra aulas na graduação e pósgraduação. Possui diversos projetos na área de ensino da QV e dentre suas linhas de pesquisa, destaca-se o Ensino de Química na Perspectiva da QV.

Vânia Gomes Zuin é licenciada e bacharel em Química (1993), mestre (1997) e doutora (2001) em Ciências pela USP. Doutorou-se também em Educação (2010) pela mesma universidade, sendo pós-doutora pelo Centro de Pesquisas Ambientais da Alemanha (2005). Fundadora e coordenadora até 2017 da Seção de QV da SBQ. É membro de comitês internacionais de QV, sendo ganhadora de títulos e prêmios na área, o que mostra sua intensa participação nesse campo. Atualmente, é professora e pesquisadora visitante da University of York (Inglaterra) e professora associada da Universidade Federal de São Carlos, onde ministra aulas de QV e desenvolve diversos projetos em linha de pesquisa sobre esse tema.

\section{Considerações finais}

A QV é apontada por Lenardão et al (2003) como uma nova tendência no modo de tratar a questão dos resíduos químicos, iniciada nos anos 90 e que pode ter seus princípios aplicados à indústria, ensino e pesquisa em química. Tendo isso em vista, este trabalho apresentou um mapeamento, a partir de 260 revistas, das publicações sobre ensino de QV no Brasil.

A partir dos gráficos, podemos perceber que algumas instituições e revistas estão mais direcionadas ao desenvolvimento de estudos e produções na área de QV e que este é um tema que está se tornando bastante visível no cenário mundial e precisa ser cada vez mais inserido no Ensino de Química, a fim de formar estudantes com uma nova conduta química, não só para suprir as necessidades da sociedade por novos produtos, mas também levando em consideração os aspectos ambientais.

O uso das redes sociais é muito útil quando se tem um conjunto grande de dados para análise, como, por exemplo, o trabalho de Chrispino et al (2013), que investigou 394 fontes 
bibliográficas a respeito da área CTS no Brasil; Melo et al (2016a) que construiu uma rede com 373 textos e seus autores sobre enfoque CTS no Brasil e, ainda, Melo et al (2016b) que apresentou uma rede com 174 palavras-chave, também na área de CTS.

Os grafos gerados a partir desses dados permitem extrair informações relevantes de modo prático, como no caso dos artigos investigados neste trabalho, no qual a análise das redes sociais trouxe à tona questões significativas sobre nosso estudo. $\bigcirc$ grafo de palavraschave, por exemplo, mostrou uma grande quantidade de redes desconexas, ou seja, embora os artigos que constituam essas redes tratem do ensino da QV, eles não são facilmente localizados pelos estudiosos da área, uma vez que suas palavras-chave não estabelecem conexão com nenhuma outra sub-rede. Ademais, o grafo de autores dos 31 artigos analisados mostrou que dois dos autores mais citados nesses trabalhos também são os que estabelecem mais conexões na rede de autores, indicando que os mesmos são fontes representativas sobre o ensino da QV no Brasil.

Por outro lado, ao investigarmos sobre as obras mais referenciadas pelo nosso universo de pesquisa, chama a atenção o fato de que estas foram citadas por menos de $30 \%$ dos artigos, o que nos leva a concluir que, embora cada obra possua contribuições relevantes para o ensino da QV, ainda há pouco consenso dentro da área.

Além disso, a análise das obras mais citadas no recorte de pesquisa deste trabalho mostrou que nenhuma delas aborda exclusivamente o ensino da QV. Três delas (MARQUES et al, 2007; LENARDÃO et al, 2003; ANASTAS e WARNER, 1998) apresentam considerações sobre meio ambiente ou sobre os princípios da QV aplicados a diversas áreas, dentre elas, a de ensino e as demais abordam as temáticas de ensino de ciências com enfoque CTS (SANTOS E SCHNETZLER, 2008; SANTOS E MORTIMER, 2002) e educação (FREIRE, 1997). Isso mostra que os estudiosos envolvidos com o ensino da QV têm buscado aporte teórico nos pressupostos da abordagem de ensino CTS e nas contribuições freireanas.

Essa compreensão é reforçada, ainda, quando percebemos que Wildson Santos é o primeiro autor mais citado nos trabalhos investigados, embora não tenha sido um pesquisador da área. É importante ressaltar que nos exercícios de pesquisa utilizando redes sociais em nosso grupo, Paulo Freire aparece na lista de mais citados, o que não quer significar que seus princípios pedagógicos estejam efetivamente sendo aplicados no trabalho ou pesquisa (BRAYNER, 2017; ROSO e AULER, 2016; ROSA e AULER, 2016).

Por fim, o estudo apresentado neste trabalho revela que o ensino da QV no Brasil tem ganhado cada vez mais espaço nas salas de aula. No entanto, dentre os 31 artigos pesquisados, nenhum deles nem suas referências apresentaram uma discussão sistematizada sobre o ensino desse tema. A maior parte do material investigado fala sobre aplicações dos princípios da QV no ensino e não sobre o ensino da QV. Sendo assim, acredita-se que o panorama inicial sobre o ensino de QV a partir da análise de redes, exposto neste trabalho, sirva não só como fonte de pesquisa para os profissionais interessados na área, mas também estimule que mais pesquisas sejam desenvolvidas contribuindo assim para o aumento da representatividade dessa temática no Brasil. 


\section{Referências}

ANASTAS, P. T.; WARNER J. C. Green chemistry: theory and practice. Oxford: university press, 1998. 132p.

AULER, D; BAZZO, W. A. Reflexões para a implementação do movimento CTS no contexto educacional brasileiro. Revista Ciência \& Educação, Bauru, v. 7, n. 1, p. 1-13, 2001.

BRAYNER, F.H.A. "Paulofreireanismo": instituindo uma teologia laica? Revista Brasileira de Educação, v.22, n.70, p.851-872, jul-set 2017.

BRAUN, B.; CHARNEY, R.; CLARENS, A.; FARRUGIA, J.; KITCHENS, C.; LISOWSKI, C.; NAISTAT, D.; O'NEIL, A. Completing Your Education: Green Chemistry in the Curriculum. Journal of Chemical Education, v. 83, n. 8, p. 1126-1129, 2006.

BYNUM, W. Uma breve História da Ciência. 1 ed. Porto Alegre-RS: L\&PM. 2013. 312p.

CHRISPINO, A.; LIMA, L. S. DE; AlBUQUeRQUE, M. B. DE; FREITAS, A. C. C. DE; SILVA, M. A. F. B. DA. A Área CTS no Brasil Vista como Rede Social: Onde Aprendemos?. Ciência \& Educação, Bauru, v.19, n. 2, p. 455-479, 2013.

CORREA, A.G.; ZUIN, V.G. Química Verde: Fundamentos e Aplicações. São Carlos: EduFScar, 2009. p. 9-11.

FREIRE, P. Pedagogia do Oprimido. São Paulo: Paz na Terra. 1997. 253p.

GREYER, R.; JAMBECK, J. R.; LAW, K.L. Production, use, and fate of all plastics ever made. Science Advanced, v. 3, n. 7, 2017.

LERNARDÃO, E. J.; FREITAG, R. A.; DABDOUB, M. J.; BATISTA, A. C. F.; SILVEIRA, C. D. C. Green chemistry: os doze princípios da química verde e sua inserção nas atividades de ensino e pesquisa. Química Nova, São Paulo, v.26, n.1, p.123-129, 2003.

MARICATO, J. M.; NORONHA, D. P. Indicadores bibliométricos e cientométricos em CT\&l: apontamentos históricos, metodológicos e tendências de aplicação. In: HAYASHI, M. C. P. I; LETA, J. (orgs.) Bibliometria e cientometria: reflexões teóricas e interfaces. São Carlos: Pedro \& João Editores, 2013.

MARQUES, C. A.; GONÇALVES, F. P.; ZAMPIRON, E.; COELHO, J. C.; MELLO, L. C.; OLIVEIRA, P. R. S.; LINDEMANN, R. H. Visões de meio ambiente e suas implicações pedagógicas no ensino de química na escola média. Química Nova, v.30, n.8, p. 2043-2052, 2007.

MARTELETO, R. M. Análise de redes sociais: aplicação nos estudos de transferência da informação. Ciência da Informação, Brasília, v.30, n.1, p.71-81, 2001.

MELO, T. B.; PONTES, F. C. D. C.; BÖCK, B., TOLEDO, C.; CHRISPINO, A. Redes sociais formadas pela revista CTS: Uma análise dos doze primeiros anos de publicações. CTS: Revista iberoamericana de ciencia, tecnología y sociedad, v.11, n.33, p.267-290, 2016a.

MElO, T. B.; PONTES, F. C. D. C.; AlBUQUerQue, M. B.; SILVA, M. A. F. B.; CHRISPINO, A. Os Temas de Pesquisa que Orbitam o Enfoque CTS: Uma Análise de Rede sobre a Produção Acadêmica Brasileira em Ensino. Revista Brasileira de Pesquisa em Educação em Ciências, v.16, n.3, p. 587-606, 2016b. 
PITANGA, A. F. Crise da modernidade, educação ambiental, educação para o desenvolvimento sustentável e educação em química verde: (re)pensando paradigmas. Revista Ensaio, v.18, n. 3, p.141-159, 2016.

REN 21. Renewable energy policy network for the $21^{\text {st }}$ century. Disponível em: <http://ow.ly/lw1F30gmij5>. Acesso em: 04 nov. 2017.

ROCHA, M. L.; GONZALEZ, A. H. G.; BRUNO, N. V.; CHRISPINO, A. Representatividade da Biologia em CTS Por Meio de Análise por Redes Sociais. Contexto \& Educação, ljuí, RS, ano 32, n. 102, p. 81-99, maio/ago, 2017.

ROSA, S. E.; AULER, D. Não neutralidade da Ciência-Tecnologia: problematizando silenciamentos em práticas educativas relacionadas a CTS. Alexandria: Revista de Educação em Ciência e Tecnologia, v.9, n.2, p.203-231, 2016.

ROSO, C. C.; AULER, D. A participação na construção do currículo: práticas educativas vinculadas ao movimento CTS. Ciência Educação, v. 22, p. 371-389, 2016.

SANTOS, W. L. P.; MORTIMER, E. F. Uma análise de pressupostos teóricos da abordagem CT-S (Ciência-Tecnologia-Sociedade) no contexto da educação brasileira. Ensaio Pesquisa em Educação em Ciências, v.2, n.2, p.110-132, 2002.

SANTOS, W. L. P., SCHNETZLER, R. P. Educação em Química: Compromisso com a Cidadania. Ed. Unijuí. 2008. 160p.

TEIXEIRA, L. A.; AGUDO, M. M.; TALAMONI, J. L. B. Análise do processo participativo em projetos ambientais desenvolvidos em um bairro de Bauru/SP. Amazônia: Revista de Educação em Ciências e Matemáticas, v. 12, n. 23, p. 70-84, 2015.

ZUIN, V. G. Trajetórias em Formação Docente: da Química Verde à Ambientalização Curricular. In: Reunião Anual da Associação Nacional de Pós-Graduação e Pesquisa em Educação, 31, 2008, Caxambu. Anais... Caxambu, 2008. 


\section{Anexo 1 - Lista de Artigos}

AGUIAR, N. V. V., SANT'ANA, A. L., MATOS, A.P. Aplicação de Conceitos da Química Verde em uma Atividade Curricular de Integração Ensino, Pesquisa e Extensão: relato de experiência a partir da UFSCar. Revista Brasileira de Ensino de Química, v.10, n.2, p. 89-95, 2015.

ALMEIDA, G. A. V., SILVA, L. M., MARCHÃO, R. L., WADT, P. G. S., DE SOUZA, A. M., DE OLIVEIRA, L. C. Métodos Kjeldahl, elementar e o potencial da espectroscopia do infravermelho próximo para determinação de nitrogênio em solos da bacia do Acre. Biota Amazônia, v.6, n.4, p.38-43, 2016.

ANDRADE, D. O. D. N., BRANCO, N. B. C., GONÇALVES, F. P. (2016). Tratamento de água com coagulante biodegradável: uma proposta de atividade experimental. Química Nova na Escola, v.38, n.4, p.375-382, 2016.

CANGEMI, J. M., SANTOS, A. M. dos, NETO, S. C. A revolução verde da mamona. Química Nova na Escola, v.32, n.1, p.3-8, 2010.

CARDOSO, A. A., MACHADO, C. D. M. D., PEREIRA, E. A. Biocombustível, o mito do combustível limpo. Química Nova na Escola, v.28, p.9-14, 2008.

COELHO, J. C., MARQUES, C. A. Contribuições freireanas para a contextualização no ensino de Química. Ensaio Pesquisa em Educação em Ciências, v.9, n.1, p.49-61, 2007.

COELHO, J. C., MARQUES, C. A. A chuva ácida na perspectiva de tema social: um estudo com professores de Química. Química Nova na Escola, v.25, p.14-19, 2007.

CORTES JR, L. P., CORIO, P., FERNANDEZ, C. As representações sociais de química ambiental dos alunos iniciantes na graduação em química. Química Nova na Escola, v.31, n.1, p.46-54, 2009.

FRAGOSO, K. M., UMBERTO, D. R., BARILI, I. C., BIANCHI, E. C., DA SILVA, R. B., AGUIAR, P. R., DE MELLO, H. J. Retificação cilíndrica do aço VP50 utilizando o rebolo de carbeto de silício verde com a técnica de MQL. Revista Matéria, v.21, n.3, p.756-766, 2016.

GONÇALVES, F. P., \& MARQUES, C. A.. Contribuições pedagógicas e epistemológicas em textos de experimentação no ensino de química. Investigações em Ensino de Ciências, v.11, n.2, p.219-238, 2016.

GONÇALVES, C. A., MELO, V. A. Lazer e urbanização no Brasil: notas de uma história recente (décadas de 1950/1970). Movimento, v.15, n.3, p.249-271, 2009.

JUNIOR, E. F. C., DEEKE, V. Implantando práticas sustentáveis nos campi universitários: a proposta do "escritório verde" da UTFPR. Revista Educação \& Tecnologia, n.9, 2009.

LEAL, A. L., MARQUES, C. A. O conhecimento químico e a questão ambiental na formação docente. Química Nova na Escola, v.29, p.30-33, 2008.

MARCELINO, L. V., MARQUES, C. A. Compreensões de professores sobre abordagens das biotecnologias no ensino de química. Alexandria: Revista de Educação em Ciência e Tecnologia, v.10, n.1, p.119-142, 2017. 
MELO, M. R., VILLANI, A. A evolução de uma professora na formação de licenciandos de Química numa perspectiva sócio-ambiental. Investigações em Ensino de Ciências, v.16, n.2, p.291-315, 2016.

MELO, M. R., VILLANI, A., SANTOS, W. B. A Química Verde como Referencial Científico para Mediação de Ensino na Perspectiva CTSA em Cursos de Formação de Professores de Química. Revista Brasileira de Ensino de Química, v.9, n.1, p.91-107, 2014.

NEU, C. V., MACHADO, C. M. L., DA COSTA, A. B., KIPPER, L. M., SOARES, M. F. M., HOMRICH, N. C., KAUFMANN, R. C. Produção de biodiesel em laboratório como ferramenta para o ensino interdisciplinar. Revista Educação \& Tecnologia, n.13, 2015.

PEREIRA, D., JOÃO, J. J., ZACCARON, A., NANDI, V. N. S. Reaproveitamento dos resíduos sólidos gerados em ensaios laboratoriais (restos de esmaltes) e fusão industrial. Revista Ciência e Tecnologia, v.19, n.34, p.43-47, 2016.

PITANGA, Â. F. Crise da modernidade, educação ambiental, educação para o desenvolvimento sustentável e educação em química verde:(re) pensando paradigmas. Ensaio Pesquisa em Educação em Ciências, v.18, n.3, p.141-159, 2016.

REGIANI, A. M., MARQueS, C. A. O Contexto Amazônico na Produção Acadêmica de Licenciandos em Química da Universidade Federal do Acre: Revelações de um Percurso Formativo. Química Nova na Escola, v.34, n.2, p.67-74, 2012.

REZENDE, W., LOPES, F. S., RODRIGUES, A. S., GUTZ, I. G. A. Efervescente Reação Entre Dois Oxidantes de Uso Doméstico e a Sua Análise Química por Medição de Espuma. Química Nova na Escola, v.30, p.66-69, 2008.

RIBEIRO, M. E. N. P., SILVA, D. M., SILVA, A. F. C. Reciclagem química do PET e seus benefícios para a sociedade e para o Ensino de Química. Revista Brasileira de Ensino de Química, v.8, n.2, p.23-32, 2013.

SANDRI, M. C. M., FILHO, O. S. Implicações da Inserção da Química Verde na Formação Inicial de Professores de Química. Revista Brasileira de Ensino de Química, v.11, n.1, p.111-125, 2016.

SANTOS, K. D., NETO, J. M. M., SOUSA, P. A. A. Química e educação ambiental: uma experiência no ensino superior. Química Nova na Escola, São Paulo, v.35, n.1, p.1-7, 2013.

SCUPINO, F., KAICK, T. S. V. Avaliação de Programas de Educação Ambiental Voltados para Gestão de Resíduos Sólidos em Escolas Municipais de Pinhais/PR. Pesquisa em Educação Ambiental, v.12, n.1, p.71-84, 2017.

Silva, T. E. M., Bernardinelli, S., DE SOUZA, F. F., MATOS, A. P., ZUIN, V. G.. Desenvolvimento e Aplicação de Webquest para Ensino de Química Orgânica: Controle Biorracional da Lagarta-do-Cartucho do Milho. Química Nova na Escola, v.38, n.1, p.47-53, 2016.

SILVA, A. F., SOARES, T. R. S., AFONSO, J. C.. Gestão de Resíduos de laboratório: uma abordagem para o ensino médio. Química Nova na Escola, v.32, n.1, p.37-42, 2010.

TREVISAN, L., JUNIOR, E. G. Gestão Ambiental: um enfoque na sustentabilidade. Revista Cultivando o Saber, v.6, n.3, p.170-181, 2013. 
ZUIN, V. G., MARQUES, C. A., ROLOFF, F. B., VIEIRA, M. S. Desenvolvimento Sustentável, Química Verde e Educação Ambiental: o que revelam as publicações da SBQ. Revista Brasileira de Ensino de Química, v.10, n.1, p.79-90, 2015.

ZUIN, V. G. A inserção da Química Verde nos programas de pós-graduação em Química do Brasil: tendências e perspectivas. RBPG: Revista Brasileira de Pós-Graduação, v.10, n.21, p.557-573, 2013.

ZUIN, V. G.. A dimensão ambiental e a Química Verde na formação inicial de professores de Química: reflexões a partir de um estudo de caso. Revista Brasileira de Ensino de Química, v.8, n.2, p.69-82, 2013. 